\title{
Model Validation for the August 10, 1996 WSCC System Outage
}

\author{
Dmitry N. Kosterev, Member Carson W. Taylor, Fellow William A. Mittelstadt, Fellow \\ Transmission Operations and Planning \\ Bonneville Power Administration \\ Portland, Oregon USA
}

\begin{abstract}
A major power outage occurred in western North America on August 10, 1996. In this paper we describe simulation of the disturbance using a transient stability program. Initially, the sequence of events was simulated using the standard WSCC dynamic data base, and the simulations did not agree with the disturbance recordings. Several model additions and data modifications were made before the simulations approximated the disturbance recordings. These model changes are discussed in the paper.
\end{abstract}

Keywords: power system modeling, power system stability, power system disturbance, power system performance high voltage direct current.

\section{THE AUGUST 10, 1996 WSCC DISTURBANCE}

On August 10, 1996, a major failure occurred in the Western Systems Coordinating Council (WSCC) system resulting in break-up into four islands, with loss of 30,390 MW of load affecting 7.49 million customers in western North America [1].

\section{A. Pre-Event Conditions and Outages}

The pre-event system conditions in the Pacific Northwest (PNW) were characterized by high north-to-south flows on the California-Oregon Intertie (COI) and the Pacific HVDC Intertie (PDCI). Figure 1 shows a one-line diagram of major $500-\mathrm{kV}$ lines in the PNW with detail of the Big Eddy area. Table 1 shows major path power flows and the percentage loading of each path rating. The PNW generation pattern was characterized by high imports from Canada, high generation in the upper Columbia (Grand Coulee, Chief Joseph) and low generation in the lower Columbia area (John Day, The Dalles). Prior to the disturbance, there were two forced outages of $500-\mathrm{kV}$ lines: John Day-Marion-Lane and Big Eddy-Ostrander. A scheduled maintenance outage of the Keeler $500 / 230-\mathrm{kV}$ transformer reduced reactive power support and voltage control at the $500-\mathrm{kV}$ bus from the static var compensator at the Keeler 230-kV bus.

PE-226-PWRS-0-12-1997 A paper recommended and approved by the IEEE Power System Dynamic Performance Committee of the IEEE Power Engineering Society for publication in the IEEE Transactions on Power Systems. Manuscript submitted July 29, 1997; made available for printing December 12, 1997.
Table 1

Power flows on major PNW paths prior to the disturbance.

\begin{tabular}{|c|c|c|c|c|}
\hline Path & $\begin{array}{c}\text { Flows } \\
\text { MW }\end{array}$ & Dir. & $\begin{array}{c}\text { Rating } \\
\text { MW }\end{array}$ & $\begin{array}{c}\text { Loading } \\
\%\end{array}$ \\
\hline California-Oregon Intertie & 4,350 & N-S & 4,800 & 91 \\
\hline Pacific HVDC Intertie & 2,850 & N-S & 3,100 & 92 \\
\hline B. C. Hydro-Northwest & 2,300 & N-S & 2,300 & 100 \\
\hline Midpoint-Summer Lake & 600 & E-W & 1,500 & 40 \\
\hline
\end{tabular}

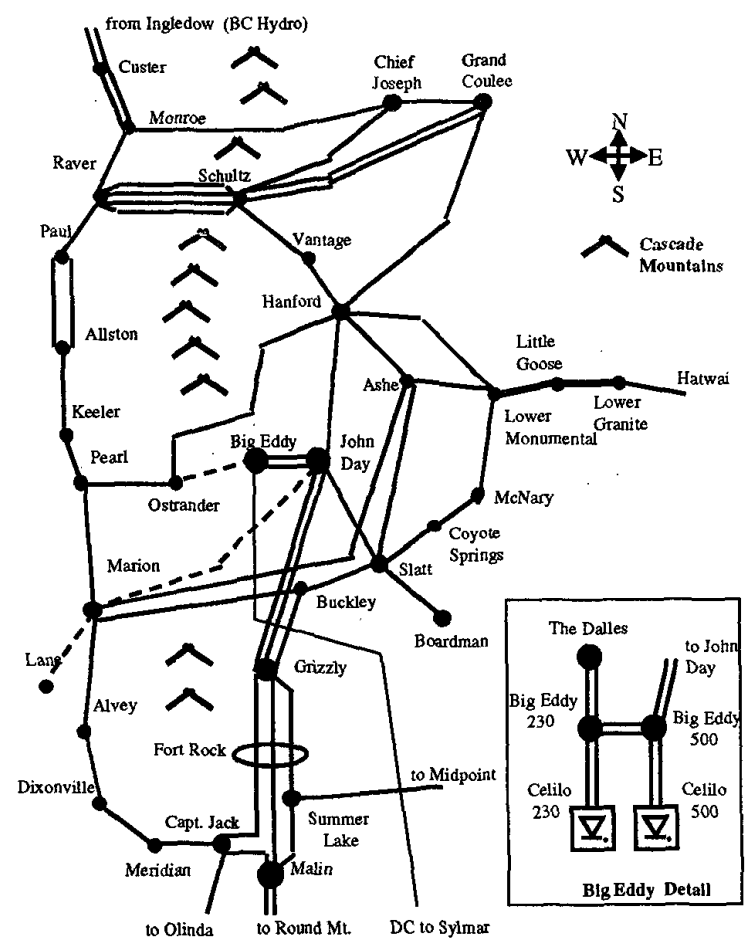

Fig. 1. One-line diagram of major $500-\mathrm{kV}$ lines in the Pacific Northwest.

\section{B. The Initial Stage of the Disturbance}

At 15:42:37, the Allston-Keeler 500-kV line sagged close to a tree and flashed over. The line was tripped following unsuccessful single-pole reclosure. Due to the Keeler breaker configuration, the Keeler-Pearl 500-kV line also opened. Prior to the outage, the Allston-Keeler line was carrying $1300 \mathrm{MW}$. This power shifted to $500-\mathrm{kV}$ lines east of the Cascades Mountains (through the Hanford bus), and to the underlying $115-\mathrm{kV}$ and $230-\mathrm{kV}$ network. The lower 
voltage lines parallel to the Allston-Keeler $500-\mathrm{kV}$ line became loaded up to $115 \%$ of their thermal ratings. Voltages in the lower Columbia area were depressed to $508 \mathrm{kV}$ at Hanford, $504 \mathrm{kV}$ at Big Eddy, $510 \mathrm{kV}$ at John Day, and 505 $\mathrm{kV}$ at McNary.

About five minutes later, the Merwin-St. Johns 115-kV line tripped due to a relay failure and the overloaded RossLexington $230-\mathrm{kV}$ sagged into a tree. These lines are parallel to the Allston-Keeler 500-kV line.

About the same time, at 15:47:37, sequential tripping of thirteen McNary units began due to exciter protection malfunctions at high field voltage. This started system power and voltage oscillations (Figure 2).

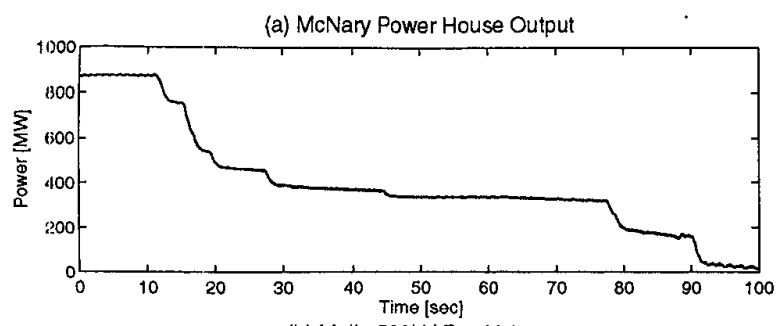

(b) Malin $500 \mathrm{kV}$ Bus Voltage

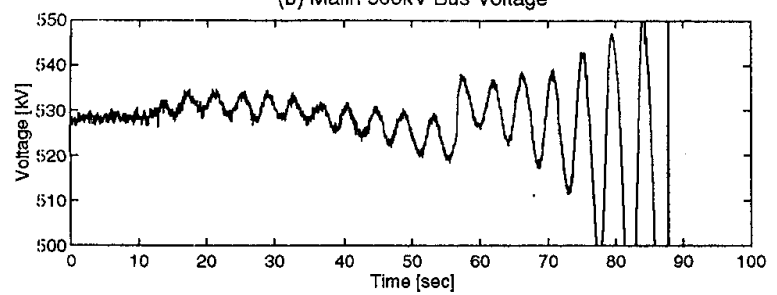

(c) California-Oregon Intertie Power

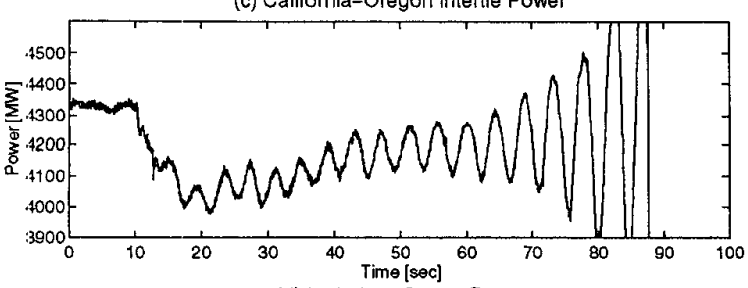

(d) Ingledow-Custer Powe

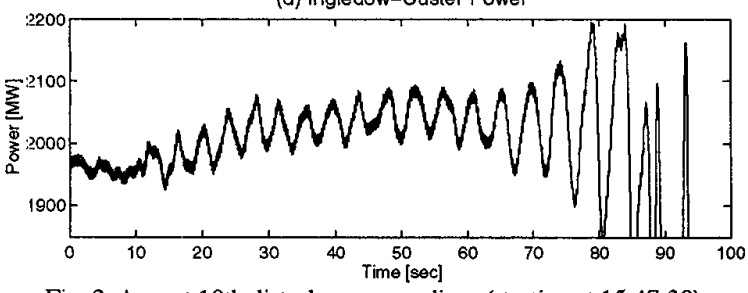

Fig. 2. August 10th disturbance recordings (starting at 15:47:30).

Figure 2 shows:

a) power output from the McNary power plant,

b) Malin $500-\mathrm{kV}$ bus voltage,

c) COI power (sum of flows in the Captain Jack-Olinda and both Malin-Round Mountain 500-kV lines), d) British Columbia-PNW tie power (both IngledowCuster 500-kV lines).

For up to 40 seconds on the plot scale, the power oscillations were sustained at near zero damping.

\section{The Final Stage before Cascading}

Following initial tripping of McNary generators, the system frequency dropped, the COI export decreased, and significant BPA area control error developed. Figure 3 shows

a) McNary generation (same as Figure 2a),

b) BPA Area Control Error, and

c) Grand Coulee unit 20 frequency.

Subsequent $\mathrm{AGC}$ and governor actions tried to restore the system frequency and the COI interchange flow. The AGC power pick-up occurred at Grand Coulee, John Day, and Chief Joseph generators. Figure 4 shows the power output increase at:

a) Grand Coulee,

b) Chief Joseph,

c) John Day.

Increase in Canadian exports due to governor action was also recorded.
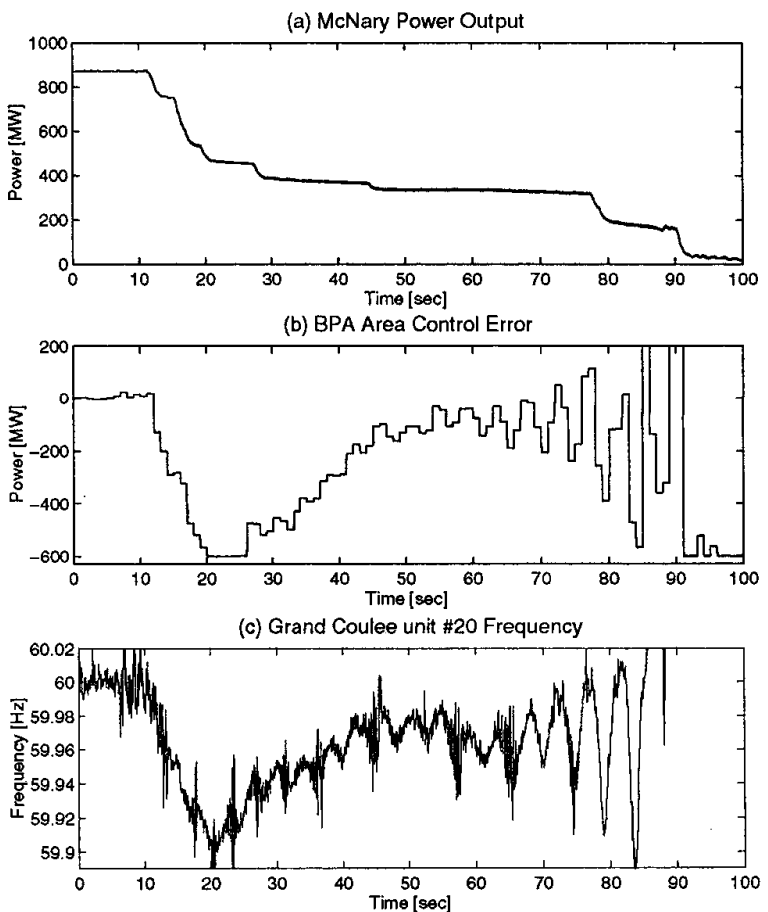

Fig. 3. Disturbance recordings of the McNary tripping, BPA Area Control Error and the Coulee generator frequency (starting at 15:47:30)

The power pick up occurred primarily in the upper Columbia area, further stressing the east of Cascades $500-\mathrm{kV}$ transmission lines, and further depressing Northwest voltages. 
(a) Grand Coulee Power Pick-Up

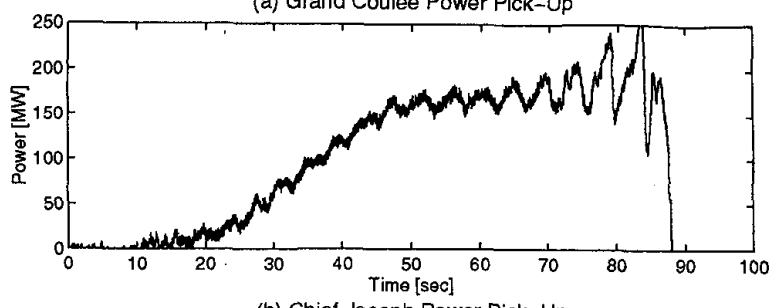

(b) Chief Joseph Power Pick-Up

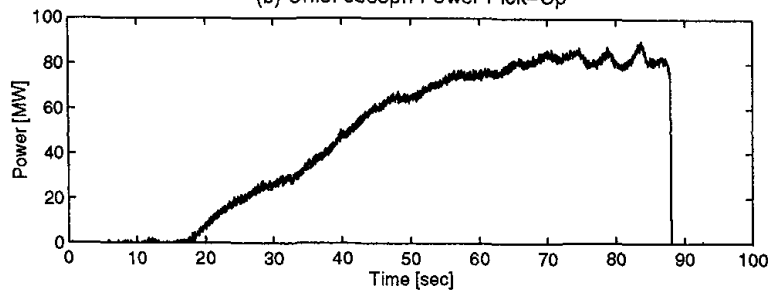

(c) John Day Power Pick-Up

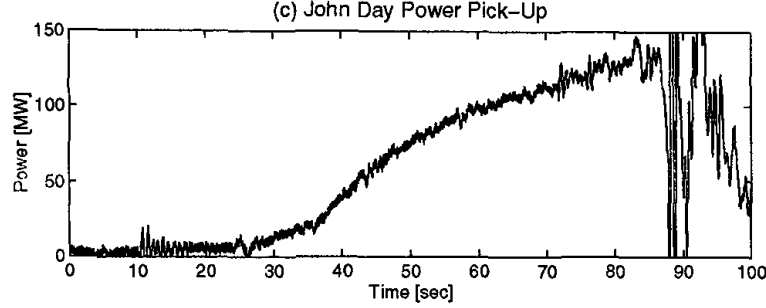

Fig. 4. Disturbance recordings of the responses of major power generation plants in the Pacific Northwest to AGC action and frequency drop following McNary tripping (starting at 15:47:30).

Due to increased line loading and limited reactive power support from lower Columbia generators, the system voltages continued to decay on average. Figure 5 shows Big Eddy and John Day 500-kV voltages from BPA SCADA (2 second data sampling).

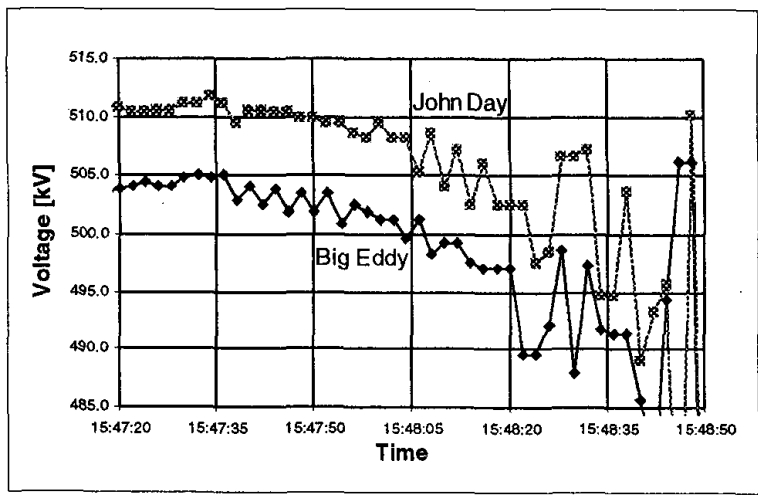

Fig. 5. BPA SCADA voltages in the Lower Columbia area

The Pacific HVDC Intertie (PDCI) has the four-terminal bi-polar configuration [2]. Each end each consists of
Existing converters and parallel Expansion converters, see the Appendix.

PDCI operates in the constant power mode at the pole level. In normal North-to-South operation, both Celilo Expansion and Existing converters are in the current control mode. The Sylmar Expansion converter operates in the mixed (extinction angle - current) control mode, and the Sylmar Existing converter is setting the dc voltage by having the converter extinction angle at its minimum value. Sylmar Existing converter LTC transformers are adjusted to control the rectifier dc voltage to $500 \mathrm{kV}$.

The PDCI was initially maintaining constant power control (Figure 6). As Celilo ac voltages continued to decay on average, the Existing converters started limiting out (reaching minimum firing angle and losing current control) during the lower portion of the ac voltage swings. During the upper portion of ac voltage swings the converters regained current control. AC voltage oscillations and converter control limits caused the PDCI power oscillations.
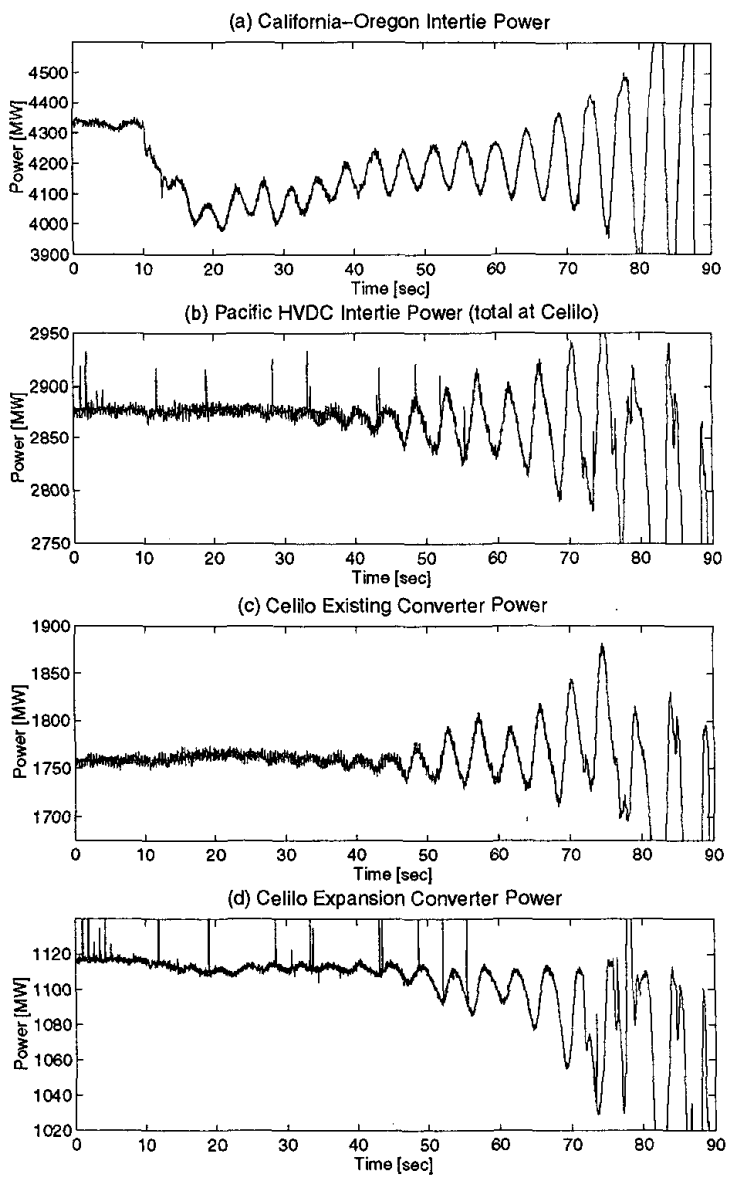

Fig. 6. Disturbance recording of the PDCl response (starting at 15:42:30) 
Present PDCI controls have a function attempting to maintain dc power constant by transferring current control from a rectifier (Celilo) to an inverter (Sylmar) when a rectifier becomes limited. The mode shift caused by this function contributed to dc power oscillations, resulting in $\mathrm{dc}$ power swings below and above the scheduled power.

Figure 6 shows:

a) COI power (same as Figure 2b),

b) total PDCI power at the Celilo converter,

c) Celilo Existing converter total power,

d) Celilo Expansion converter total power.

As the PDCI started participating in the oscillations, the ac system oscillations started picking up in magnitude and the COI separation occurred at 15:48:52 (lines relayed due to low voltage high current conditions). The resulting cascading [1] is outside the scope of this work.

\section{Analysis of the Oscillations}

Prony analysis [3] identified oscillatory components of power quantities on major $\mathrm{AC}$ and $\mathrm{DC}$ paths. The oscillation "signature" changed as the transient progressed. At initial stages, the oscillation frequency was $0.266 \mathrm{~Hz}$ with near zero damping (Prony analysis of the Malin voltage oscillations on the interval 20-35 seconds on the plot scale). With the AGC power pick-up, the oscillatory frequency decreased to 0.242 $\mathrm{Hz}$ and damping changed to $-2.66 \%$ (Prony on the interval 35-50 seconds on the plot scale). As the PDCI started participating in the oscillations, the oscillation frequency continued to decrease and the system damping became more negative. At the final stage of the event, the oscillatory frequency was $0.217 \mathrm{~Hz}$ with damping of $-7.62 \%$ (Prony on the interval $72-84$ seconds).

We computed amplitude and phase of the power oscillations for the COI, Celilo Expansion converter power, Celilo Existing converter power, Celilo total power, Grand Coulee power output, and the British Columbia-Northwest tie power. The complex plane in Figure 7 shows phase relationship between the specified power oscillations. This phase relationship corresponds to the mode shape for the approximately $0.23 \mathrm{~Hz}$ oscillations. Note that the Celilo Expansion and Existing converters had different behavior and impact on the system oscillations.

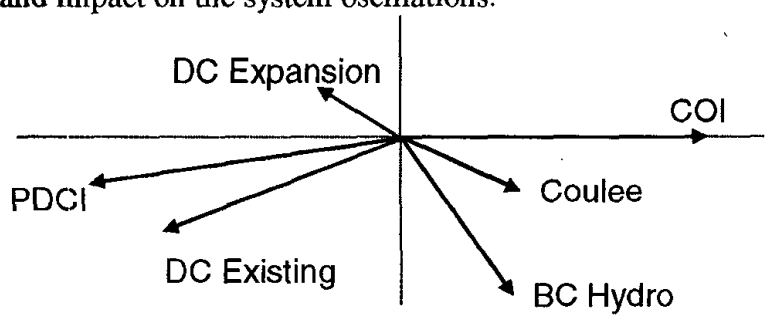

Fig. 7: phasor diagram of power oscillations at $0.23 \mathrm{~Hz}$

\section{AUGUST 10'TH VALIDATION STUDIES}

We simulated the disturbance using the EPRI ETMSP program to verify the system dynamic models used in planning and operational studies.

First, pre-event power flow conditions were accurately represented using the SCADA data just prior to the RossLexington line outage.

\section{A. Validation Criteria for the Time-Domain Simulations}

The main intent of the validation studies was to capture the mechanism and driving forces which led to the system instability. Correct system reinforcements can then be identified and operating practices can be established to prevent similar outages from reoccurring. The system simulations are tested by the following criteria:

1. Frequency and damping of the inter-area oscillatory mode as well as their changes as the disturbance progressed.

2. Change in the PDCI behavior from constant power mode to power oscillations.

3. Average profile of the system voltages, line flows, and system frequency.

4. Distribution of the oscillatory mode in the system (phase shift between power oscillations at the COI, PDCI, Coulee, and British Columbia-PNW ties).

\section{B. Time-Domain Simulations using the WSCC Dynamic Models and Data}

Initially, the August 10th sequence of events was simulated using the standard WSCC dynamic data base. This data base was assembled from dynamic data provided by individual utilities.

Figures 8-11 compare recorded and simulated data (Malin voltages, COI power, Grand Coulee frequency, and PDCI power respectively). The plots show that the response of the simulated system model does not agree with the recorded system response. Specifically, the simulated system fails to capture:

a) Damping of the inter-area oscillations. The simulated system shows stable well-damped response.

b) Averaged voltage and power profiles. The simulated system does not indicate voltage decay in the system. Also, the simulated COI power does not increase following as the transient progresses, because no AGC action was modeled following initial tripping of McNary generators.

c) PDCI mode shift and power oscillations. The simulated PDCI maintains constant power control and does not participate in oscillations.

d) System frequency excursion. The simulated frequency dip following McNary tripping is only $60 \%$ of the recorded. 

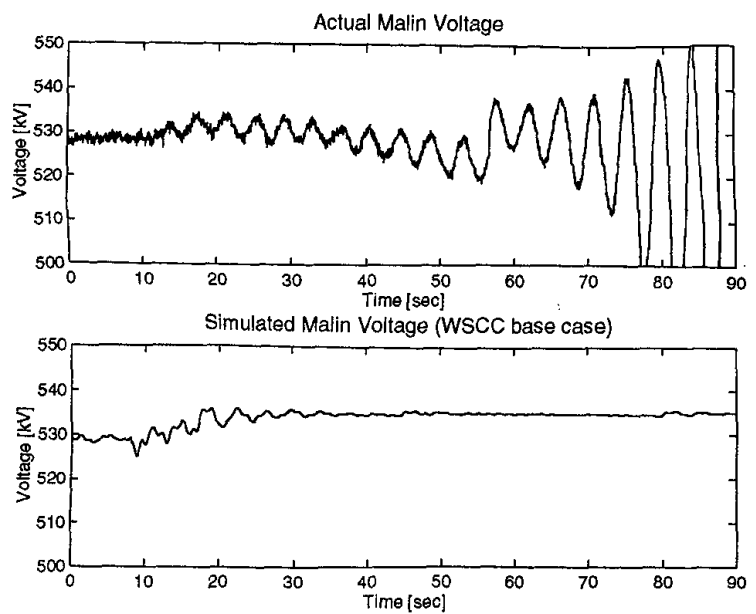

Fig. 8. Malin 500-kV voltage - recorded and simulated using WSCC data base
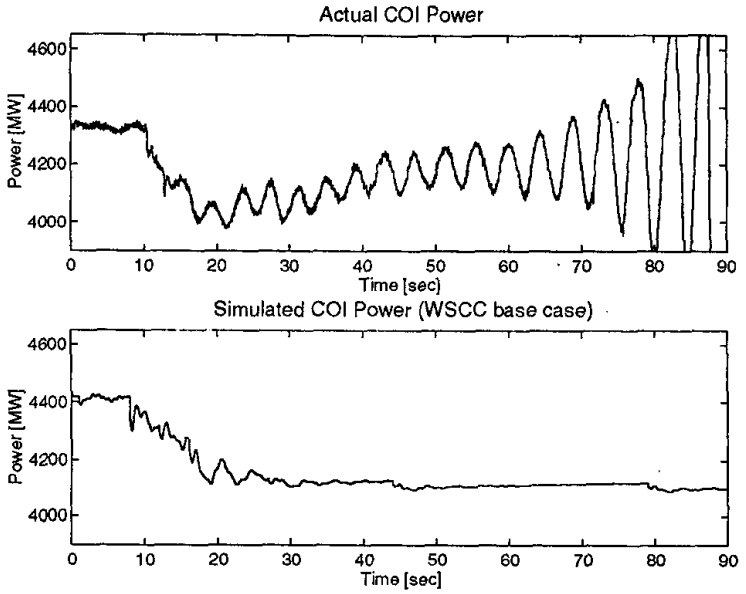

Fig. 9. COI power - recorded and simulated using WSCC data base
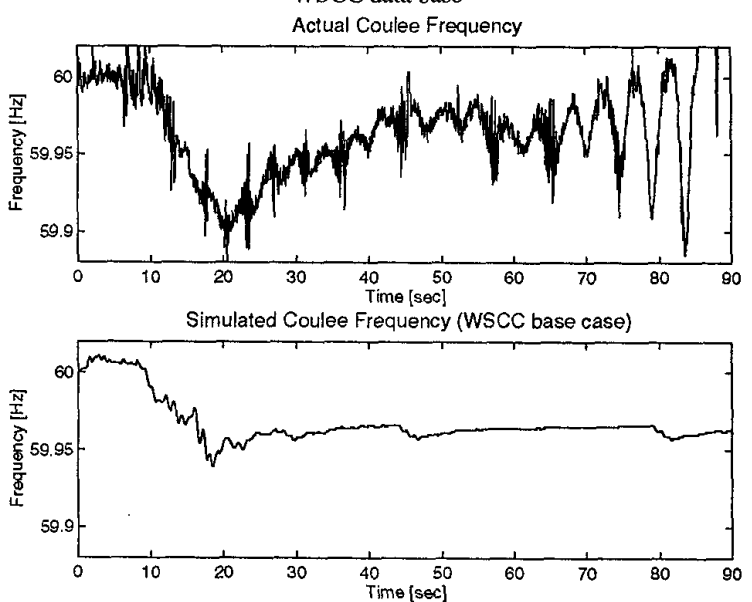

Fig. 10. Grand Coulee unit 20 frequency - recorded and simulated using WSCC data base
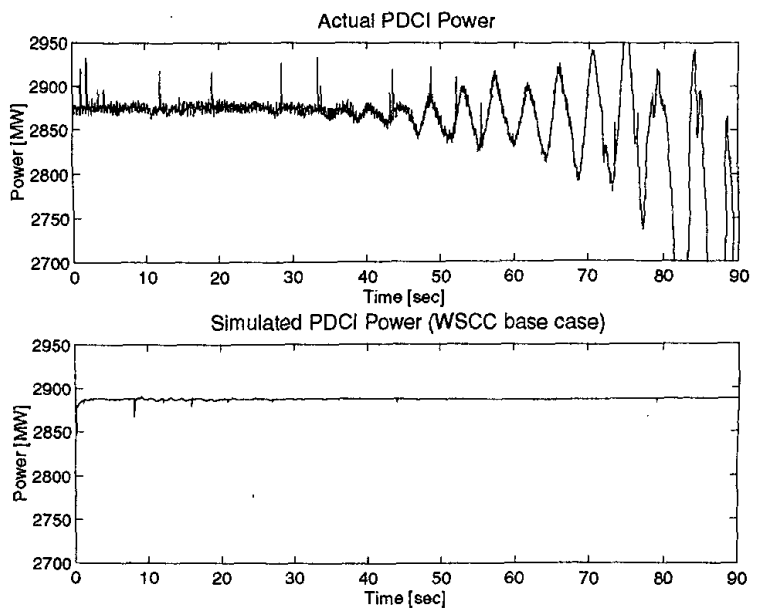

Fig. 11. PDCI power - recorded and simulated using WSCC data base

\section{Dynamic Data Modifications and Model Additions}

We modified the modeling as follows:

1) Detailed PDCI Model: The PDCI model in WSCC data base is two-terminal and has over-simplified control representation with current regulators. The model was inadequate to represent the PDCI behavior during the disturbance. A detailed stability model of the Pacific HVDC Intertie and its controls was developed by BPA. The model is four terminal and represents essential controls on the bipolar, polar, station, and converter levels [2]. The model correctly captures the PDCI mode shift during the disturbance and its impact on system damping.

2) Automatic Generation Control Action: AGC action is represented at Grand Coulee, Chief Joseph and John Day power plants. These plants were on AGC control during the disturbance. Governors at those plants are represented by user-defined models with an additional AGC input. Typically, AGC is not considered in dynamic simulation.

3) Blocking turbine-speed controls on large steamturbine generators throughout WSCC: Depending on plant design and operating practices, large turbo-generators may not increase power output immediately following the system frequency decay. If operated in turbine-follow mode, it may take minutes before boilers respond to system frequency excursion $[4,5]$. Therefore governors for large turbogenerators were not represented. No changes were made for hydro generation. This modification resulted in very close agreement between the recorded and simulated system frequency excursions following initial tripping of the McNary generators.

4) Voltage Controls on Lower Columbia generators: The US Army Corps of Engineers (Corps) operates hydro plants in the Lower Columbia area. The Corps uses Data Acquisition and Control Systems (DACS) for high-side 
voltage control and balancing of reactive power of the many hydro plant generators. As described above, voltages in the lower Columbia area were depressed for over five minutes following the Allston-Keeler $500-\mathrm{kV}$ line outage. The DACS operate in this time frame to bring the generator reactive power output within unit capability curves. The DACS action is represented at John Day, The Dalles, and Bonneville generators. Action of overexcitation limiters is modeled at McNary generators. Hermiston (near McNary) and Coyote Springs combined-cycle plants were in power factor control, limiting their reactive power support. Reactive power output at Boardman was reduced by operator intervention, so that the plant excitation system is represented by a constant field voltage in the simulations. Representing these voltage controls allowed matching of the recorded and simulated voltages in the lower Columbia area.

5) Load Modifications: After all the above system changes were made, the simulated system still showed more damping than the actual system. Load modifications were made to improve the comparison. In WSCC data base, loads in Northwest and Canada are represented by constant current characteristics. On Saturday August 10th, area loads were characterized by air conditioning loads in the metropolitan areas and irrigation loads in the rural areas. A combination of induction motors and various static loads were used in the studies.

\section{Validation Studies with Modified Dynamic Data}

We simulated the August 10th sequence of events using the modified dynamic data base. The comparison between recorded and simulated waveforms is shown on Figures 1217 (Malin voltages, COI power, Grand Coulee frequency, and PDCI power respectively). There is very good agreement between the recorded and simulated quantities.
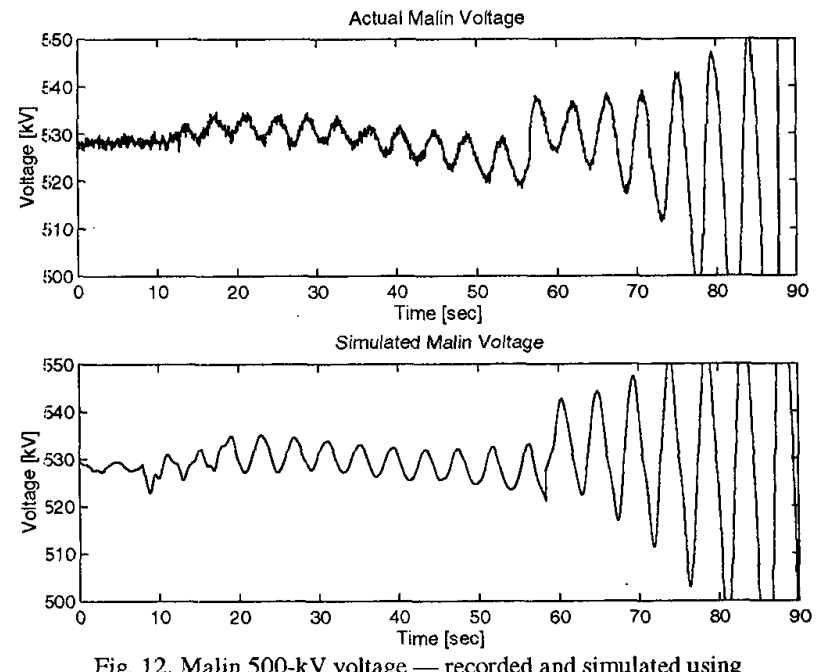

Fig. 12. Malin 500-kV voltage - recorded and simulated using modified data base
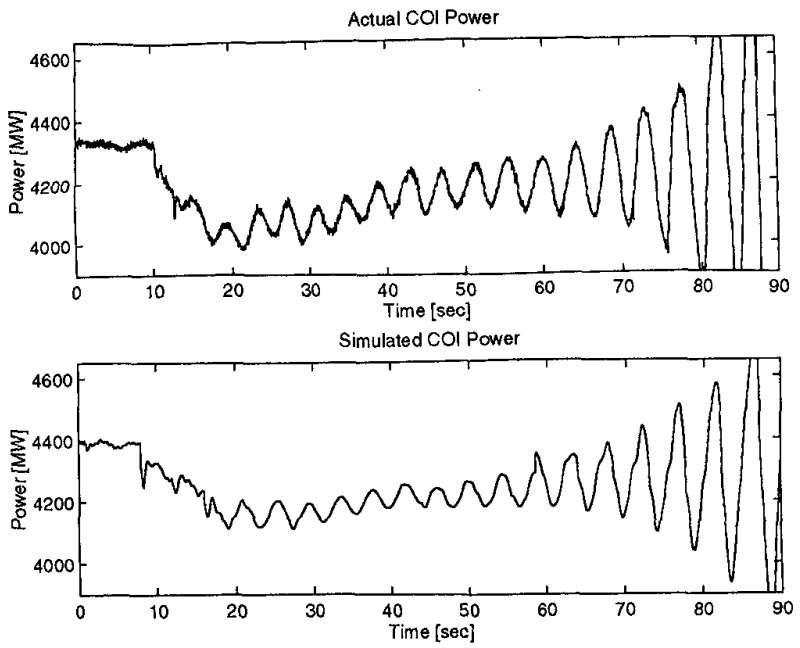

Fig. 13. COI power - recorded and simulated using modified data base
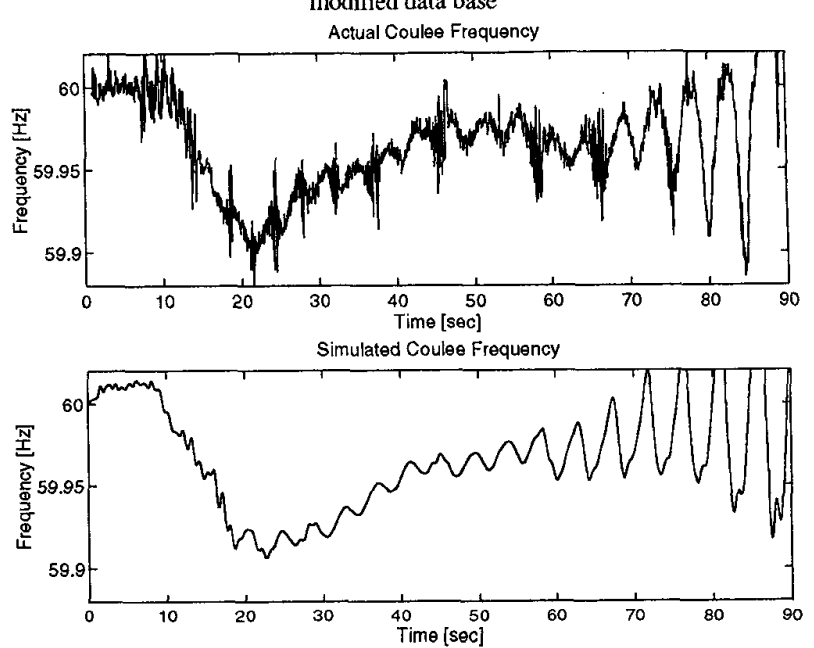

Fig. 14. Grand Coulee unit 20 frequency - recorded and simulated using modified data base
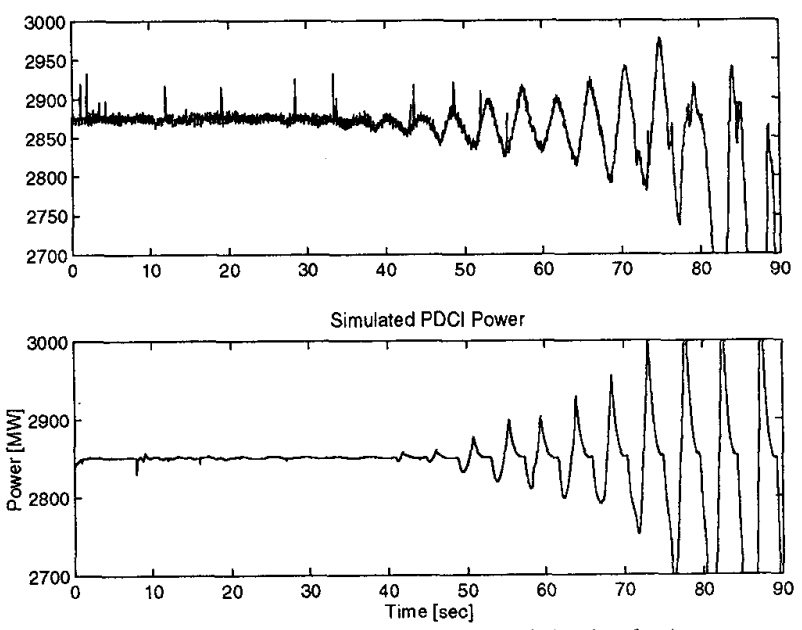

Fig. 15. PDCI total power - recorded and simulated using the modified data base 

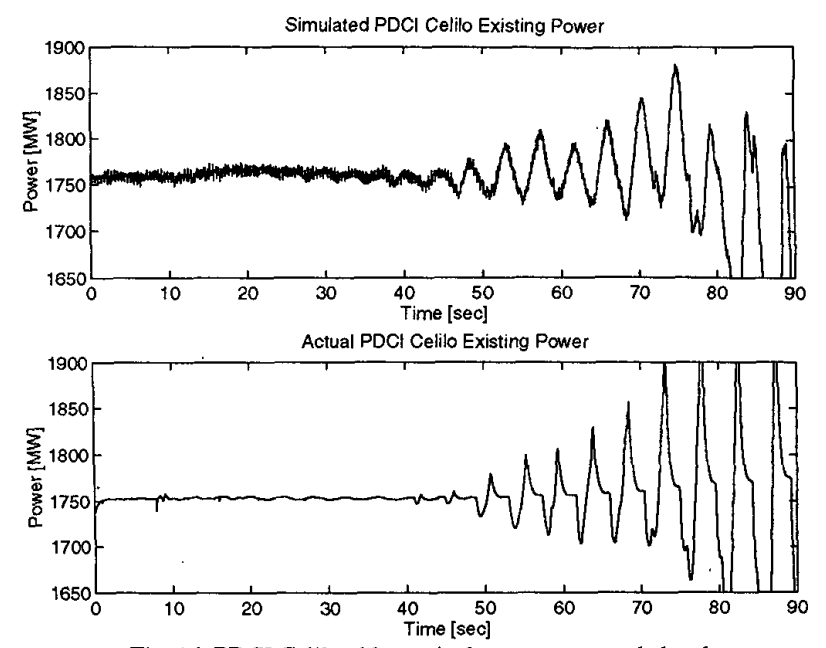

Fig. 16. PDCI Celilo old terminal power - recorded and simulated using modified data base
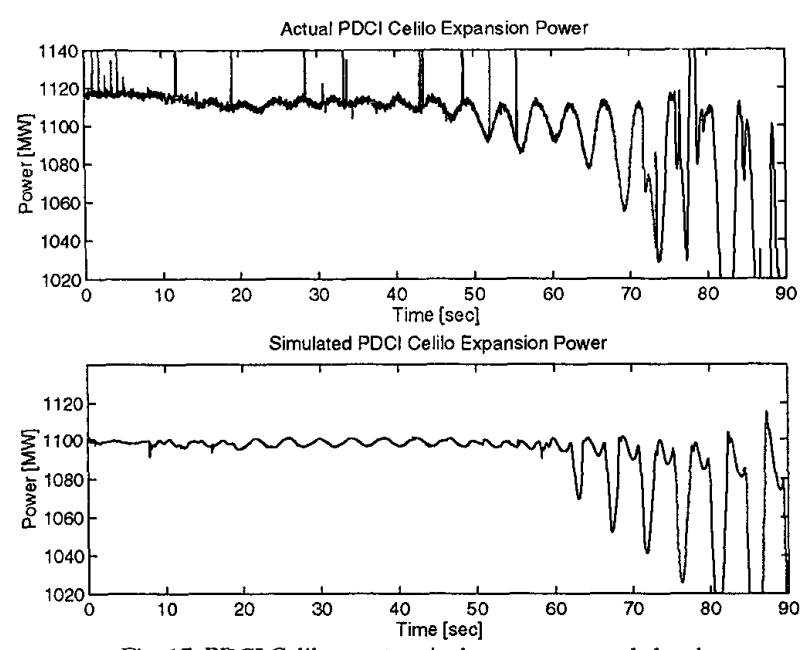

Fig. 17. PDCI Celilo new terminal power — recorded and simulated using BPA-modified data base

The modified model meets with the validation criteria: 1. The frequency and damping of the inter-area oscillatory mode are computed for the actual and simulated Malin voltages at the beginning and end of the oscillations, and presented in Table II.

Table II

Frequency and Damping of the Malin Voltage Oscillations

\begin{tabular}{|c|c|c|}
\hline Time Frame & Recorded & Simulated \\
\hline Beginning of Oscillations & $0.266 \mathrm{~Hz} @ 0 \%$ & $0.247 \mathrm{~Hz} @ 0 \%$ \\
\hline After AGC Pick-Up & $0.242 \mathrm{~Hz} @-2.66 \%$ & $0.237 \mathrm{~Hz} @-2.62 \%$ \\
\hline Prior to Break-up & $0.217 \mathrm{~Hz} @-7.62 \%$ & $0.208 \mathrm{~Hz} @-6.35 \%$ \\
\hline
\end{tabular}

2. Figures 15-17 indicate that the simulated PDCI behavior and mode shift are identical to those observed during the actual event. The behavior of individual converters agrees well with the recordings.

3 . Figures 12-14 show that average profiles of the COI power, system voltages and frequency agree with the recordings.

4. Phase shift between simulated power oscillations on the COI, British Columbia-PNW ties, Coulee, and PDCI is close to the recorded.

\section{CONCLUSIONS}

1. The existing WSCC system dynamic data base was inadequate to simulate the August 10, 1996 WSCC outage.

2. The modified data base allowed a good reproduction of the August 10, 1996 event based on comparison of timedomain simulations with disturbance recordings. The modifications include:

a) a detailed Pacific HVDC Intertie model,

b) action of BPA Automatic Generation Controls,

c) blocking turbine-speed controls on large steam-turbine generators,

d) action of high-side voltage controls on the lower Columbia hydro power plants,

e) dynamic load representation.

Model changes from the validation studies are used in operating transfer capability studies by WSCC utilities on an interim basis.

3. A continuing effort by WSCC utilities is needed to improve dynamic models used in studies of inter-connected power system. The WSCC has a large program underway to verify power plant dynamic data. Development and use of dynamic load models is highly desirable [6].

4. Based on the validation study results, the BPA has pursued various transmission system reinforcements to improve system reliability. These reinforcements include schemes for fast insertion of series and shunt capacitors, improvement of PDCI dynamic control characteristics, and modulation controls.

\section{ACKNOWLEDGMENTS}

We gratefully acknowledge contributions by many engineers. Richard Bunch (BPA) was our expert on modeling the PDCI controls. Dr. John Hauer (Battelle Pacific Northwest Laboratory) contributed to the Prony analysis of power oscillations. Solomon Yirga (Powertech Labs), and Mani Venkatasubramanian and his students (Washington State University) performed initial simulations and eigenanalysis, as well as load sensitivity studies. Gary Keenan and Ravi Aggarwal (BPA) helped prepare the dynamic data. Many WSCC engineers helped prepare the power flow base case. 


\section{REFERENCES}

[1] Western Systems Coordinating Council (WSCC), Disturbance Report for the Power System Outage that Occurred on the Western Interconnection on August 10th, 1996 at 1548 PAST, October 1996. Available at www.wscc.com.

[2] A. Hammad, R. Minghetti, J. Hasler, P. Eicher, R. Bunch, and D. Goldsworthy, "Controls Modeling and Verification for the Pacific Intertie HVDC 4-Terminal Scheme," IEEE Transactions on Power Delivery, Vol. 8, No. 1, pp. 367-375, January 1993.

[3] J. F. Hauer, "Application of Prony Analysis to the Determination of Modal Content and Equivalent Models for Measured Power System Response," IEEE Transactions on Power Systems, Vol. 6, No. 3, pp. 1302-1313, August 1995.

[4] IEEE Committee Report, "MW Response of Fossil Fueled Steam Units," IEEE Transactions on Power Apparatus and Systems, vol. PAS-92, no. 2, March/April 1973.

[5] EPIC Engineering Company, Impacts of Governor Response Changes on the Security of North American Interconnections, EPRI Report TR-101080, October 1992.

[6] IEEE Load Representation for Dynamic Performance Task Force, "Standard Load Models for Power Flow and Dynamic Performance Simulation," IEEE Transactions on Power Systems, Vol. 10, No. 3, pp. 1302-1313, August 1995.

\section{BIOGRAPHIES}

Dmitry N. Kosterev ( $\mathbf{M}^{\prime}$ 97) received his $\mathrm{Ph} . \mathrm{D}$. degree in Electrical Engineering from Oregon State University in 1996. Dr. Kosterev is currently with NSR at the Bonneville Power Administration, Transmission Operations and Planning. $\mathrm{He}$ is involved in operating studies for the California-Oregon Intertie projects, Pacific HVDC system modeling and controls, and widearea. monitoring systems. Dr. Kosterev was responsible for the validation studies of the August 10, 1996 disturbance at BPA.

Carson W. Taylor (F'88) joined Bonneville Power Administration in 1969 after earning degrees from the University of Wisconsin and Rensselaer Polytechnic Institute. His current position is Principal Engineer in Transmission Operations and Planning. Mr. Taylor is a Fellow of the IFEE. He chairs the IEEE Power System Stability Controls Subcommittee. He has also convened three CIGRÉ task forces. Mr. Taylor is the author of the EPRI-sponsored book Power System Voltage Stability and has authored or co-authored many IEEE and CIGRÉ papers. Mr. Taylor also operates Carson Taylor Seminars, a training and consulting company established in 1986.

William A. Mittelstadt (F'92) received B.S. and M.S. degrees in Electrical Engineering from Oregon State University in 1966 and 1968 respectively. Mr. Mittelstadt currently is Principal Transmission System Planning Engineer at the Bonneville Power Administration, where he responsible for a wide range of efforts related to system planning and reliability. He has participated in various technical committees in WSCC, IEEE, and CIGRE. Mr. Mittelstadt is a registered Professional Engineer in the state of Oregon.

\section{APPENDIX}

The PDCI connects the Pacific Northwest (Celilo station) with the Los-Angeles area (Sylmar station) by a $1,361 \mathrm{~km}$ direct current line. The original bi-polar HVDC system was commissioned in 1970 as a $+/-400 \mathrm{kV}, 1800 \mathrm{~A}$ scheme. Each converter consisted of three $133 \mathrm{kV}$ mercury arc groups. In 1979 , the converter current rating was increased to $2000 \mathrm{~A}$. In 1985 , the terminals were upgraded to $+/-500 \mathrm{kV}$ by adding a $100 \mathrm{kV}$ thyristor group in series with the existing mercuryarc groups. In 1989, the system was expanded by adding $1100 \mathrm{~A},+/-500 \mathrm{kV}$ thyristor converter terminals in parallel with the Existing converters.

Presently, the Pacific HVDC intertie is capable of transmitting up to $3100 \mathrm{MW}$ in either North-to-South or South-to-North directions. A one-line diagram of the present Pacific HVDC intertie configuration is shown in Figure A1 (for one pole).

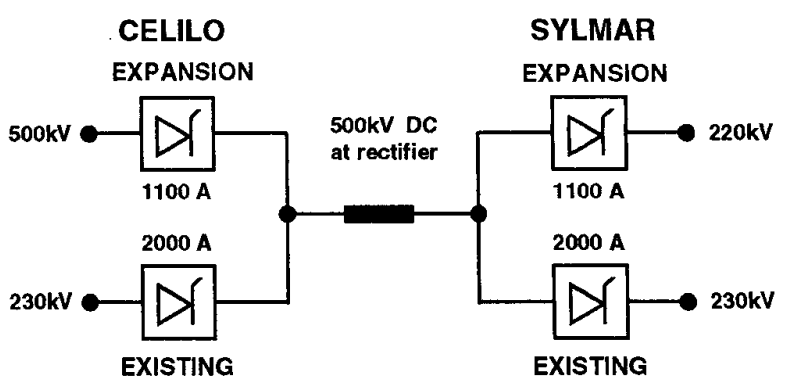

Figure A1: PDCI block-diagram

The PDCI controls have a hierarchical structure. PDCI normally operates in power control at the pole level. Pole controls compute current references for individual converters, subjected to various static and dynamic constrains. The converter controls are different for the Expansion and Existing converters. While the Existing converter controls are proportional current regulators, the Expansion converter controls are of integral type with several operating characteristics. Converter controls use different set of parameters depending on rectifier or inverter mode of operation. 


\section{Discussion}

Kip Morison, Solomon Yirga, , and Prabha Kundur (Powertech Labs Inc.): The authors are to be complimented for a well written paper describing some important modelling issues in the replication of the August 10, 1996 WSCC system disturbance. However, there are a number of critical issues which are not presented in the paper and which merit discussion.

\section{Fundamental Nature of the Phenomenon}

In determining critical modelling issues, it is essential to understand the fundamental phenomenon causing system instability. It is well known that the WSCC system is prone to lightly damped low frequency interarea oscillations in the frequency range of $0.2-0.3 \mathrm{hz}$; they have been observed on the system many times. These oscillations are a characteristic of groups of machines oscillating against other groups of machines through weak ties. This is a phenomenon associated with small-signal stability, and is a function primarily of network/generator topology and excitation controls; our studies have shown the August $10^{\text {th }}$ event to be of this nature.

Following the Merwin-St. Johns $115 \mathrm{kv}$ line tripping and the initiation of the dropping of the McNary units, the structure of the WSCC system became such that it exhibited small-signal instability and the $0.28 \mathrm{hz}$ oscillations became very pronounced. Although the actions of HVdc and AGC ultimately had some impact on the system damping and frequency of the system oscillations, they were not the fundamental cause. This is a conclusion which we have demonstrated by timedomain simulation and further illustrated by eigenvalue analysis [1]. Using eigenvalue analysis to determine which machines are contributing to the oscillations and which controls are most impactive, simple modifications to the power system stabiliziers (PSS) on just three plants in Southern California can be shown to eliminate the

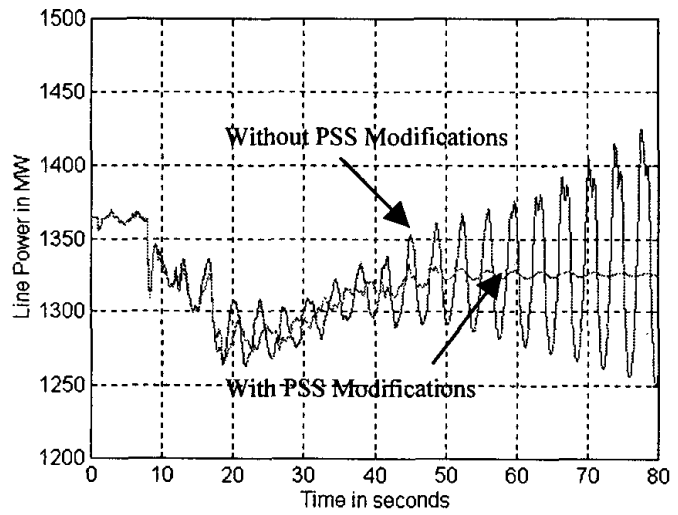

Figure I : Effect of PSS Modifications on Simulation Results

undamped oscillations completely (see Figure 1) and prevent system instability; clearly demonstrating that this is indeed a small-signal stability problem. Also, it is important to note that although system voltages were indeed depressed during the incident, it can be demonstrated that the instability would have occurred even if voltages were much healthier. The impact of capacitor additions on damping is shown in Table 1 .

\section{Critical Modelling Issues}

The authors present some interesting work in demonstrating the importance of accurate modelling of HVdc, AGC, turbine speed controls, and generator voltage controls in matching certain simulated quantities (such as frequency) to recorded responses. However, the authors have failed to show their relative importance in affecting the stability of the system.

Our analysis has shown that by far the two most critical modelling elements in reproducing this oscillatory disturbance are load characteristics and generator excitation controls. Both are relatively uncertain (particularly load) and changes to either can profoundly change the system response. In fact we were able to obtain the undamped oscillations and replicate the actual system response without resorting to the use of dynamic load models. With the "standard model" (the original WSCC model as described in the paper), the system was well damped. As the percentage of constant MVA load is increased, the system damping decreases drastically. Table 1 shows how the system damping changes in response to modelling modifications. Figure 2 shows the dramatic impact on system stability of modifications made to load only.

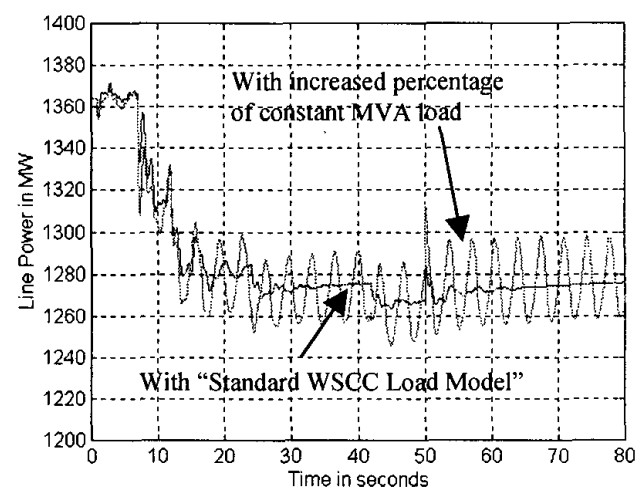

Figure 2 : Impact of Load Modelling

\begin{tabular}{|l|c|}
\hline \multicolumn{1}{|c|}{ Simulation Model } & $\begin{array}{c}\text { Damping of } \\
\text { Critical Mode }\end{array}$ \\
\hline Standard WSCC Base Model & $8.1 \%$ \\
\hline Load Model Modifications & $-1.2 \%$ \\
\hline Load Model Modifications + AGC modeled & $-3.2 \%$ \\
\hline $\begin{array}{l}\text { Load Model Modifications + AGC modeled } \\
\text { + John Day Capacitor added }\end{array}$ & $-2.7 \%$ \\
\hline
\end{tabular}

Table I: Impact on Damping of Various Modelling Changes 


\section{Preventing Future Disturbances}

While we appreciate the authors intentions in replicating the system response through simulation, we feel a different perspective on modelling is needed when studying the WSCC system. To prevent exposure to similar disturbances in the future requires analysis and mitigation of the fundamental stability phenomena occurring in the system. The lesson from August $10^{\text {th }}$, is that the WSCC system is prone to small-signal instability. To study this type of system we must,

(a) Use appropriate models in simulations. For smallsignal stability assessment, the most critical and uncertain models are load characteristics and generator excitation controls.

(b) Use appropriate study methods. In addition to timedomain simulations and Prony analysis presented by the authors, eigenvalue analysis is invaluable in assessing and tuning controls. Also, the system must be studied as a whole, and controls adjusted with due regard to low frequency inter-area oscillations.

\section{Reference}

[1] EPRI Final Report TR-108256 "System Disturbance Stability Studies for Western System Coordinating Council (WSCC)," September 1997, prepared by Powertech Labs Inc.

Manuscript received February 18, 1998.

JOHN F. HAUER (Pacific NorthWest National Laboratory): The authors have produced an excellent piece of technical work. Speaking unofficially for the WSCC's System Oscillations Work Groups (SOWG), I would like to address the decline in engineering rescurces that has made that work necessary.

Both of the WSCC breakups in the summer of 1996 were the result of known problems that had persisted for too long. To some extent this reflects a progressive fragmenting, and effective loss, of collective knowledge under the erosive pressures of utility restructuring. It also reflects an emerging attitude toward system reliability that is very different from that of the former regulated power industry.

From 1988 to 1994 the WSCC, through SOWG, conducted a massive effort to improve its planning models and its planning practices [1-4]. Key findings, based upon many tests and disturbances, were that

- The risk of $0.7 \mathrm{~Hz}$ oscillations is overestimated.

- The risk of $0.35 \mathrm{~Hz}$ (PACI) oscillations is underestimated. "This could become important as imports from Canada increase and Canadian generation resources expand northward." [3]

- Modeling for prime movers is quite optimistic, and affects damping estimates.

- Greater emphasis and resources should be given to

- direct (measurement based) analysis.

- advanced analysis tools.

With the arguable exception of HVDC effects, it appears that all of the modeling problems and repairs found by the authors are among those reported some years earlier by SOWG. The authors comments on this would be appreciated.

SOWG advocated and, just a few years ago, drew upon a much richer technical infrastructure than most planners enjoy today. Prony analysis and the operating records that the authors use so extensively are both products of the SOWG effort. At BPA, support of SOWG model validation work was an important formal requirement in development of the monitor facilities that recorded the cascading outages of July 2 and August 10 . Recommendations in [2] underlie most and perhaps all of the monitor projects in the WSCC.

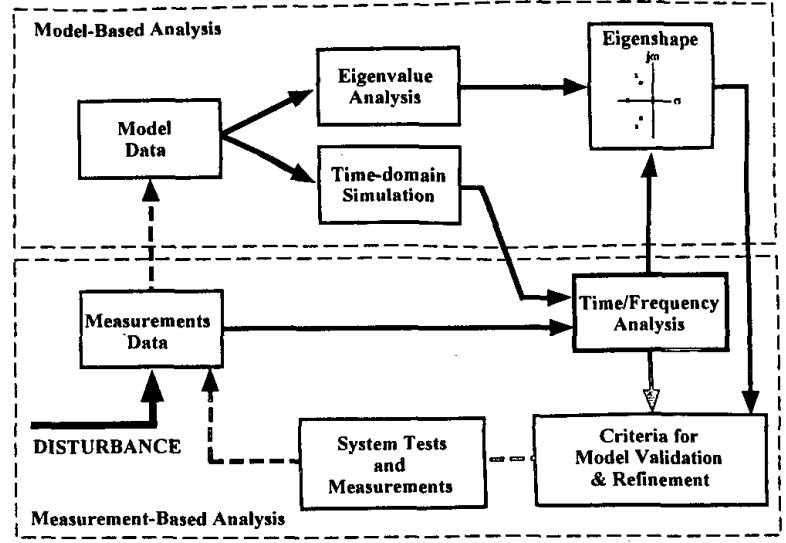

Fig. H1. Systems analysis for model validation.

SOWG was, in effect, a template for a "virtual" systems engineering staff distributed across multiple institutions. Its work in model validation, represented in Fig. H1, required a range of staff skills and tools that would rarely be found within a single utility. Very similar resources and workflow are needed for wide area control (e.g., FACTS), for which SOWG had essential support responsibilities to the WSCC [2,4]. Is some new organization evolving to resume such functions?

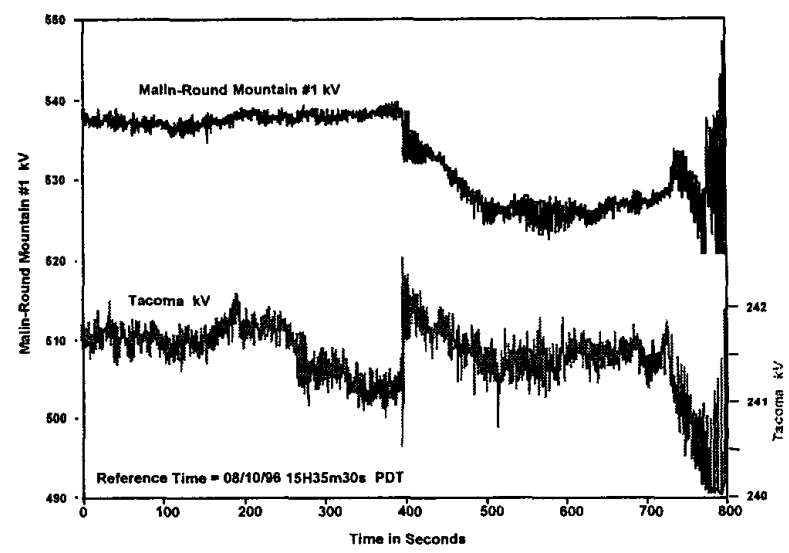

Fig. H2. Voltage signatures following Keeler-Allston line trip on August 10, 1996.

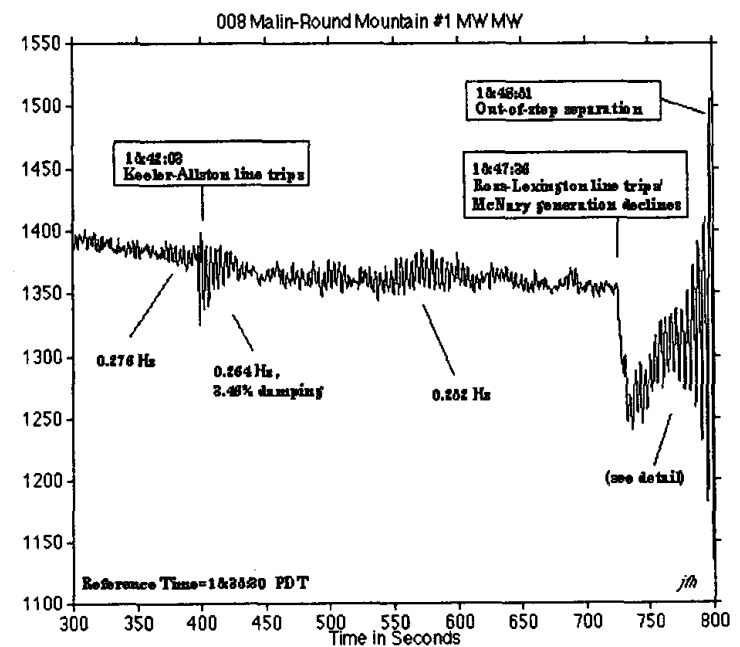

Fig. H3. Oscillation buildup for the WSCC breakup of August 10, 1996. 
Table H1. Observed behavior of the PACI mode Date/Event 12/08/92 (Palo Verde trip) 03/14/93 (Palo Verde trip) $07 / 11 / 95$ (brake insertion) Frequency $0.28 \mathrm{~Hz}$ $0.33 \mathrm{~Hz}$ $0.28 \mathrm{~Hz}$

$0.22 \mathrm{~Hz}$

Damping

$7.5 \%$

$4.5 \%$

$10.6 \%$

$1.2 \%$

PACI mode on August 10, 1996

Time/Event
10:52:19 (brake insertion)
14:52:37 (John Day-Marion)
15:18 (ringing)
15:42:03 (Keeler-Allston)
15:45 (ringing)
15:47:40 (osc. startup)
15:48:50 (osc. finish)

$\begin{array}{cc}\text { Frequency } & \text { Damping } \\ 0.285 \mathrm{~Hz} & 8.4 \% \\ 0.264 \mathrm{~Hz} & 3.7 \% \\ 0.276 \mathrm{~Hz} & \\ 0.264 \mathrm{~Hz} & 3.5 \% \\ 0.252 \mathrm{~Hz} & \\ 0.238 \mathrm{~Hz} & -3.1 \% \\ 0.216 \mathrm{~Hz} & -6.3 \%\end{array}$

As to technical details, records from the August 10 breakup should provide a very fruitful base for research. Figures $\mathrm{H} 2-\mathrm{H} 3$ show indications of impending trouble for several minutes before actual breakup on August 10. While Table $\mathrm{H} 1$ indicates unusually low frequency and damping for the PACI mode following both line trips, voltage recovery was much more robust for the earlier trip. On-line use of such signature information, as a form of measurement based dynamic security analysis, would be a useful precaution against errors in estimating transfer capacities [5]

Other salient issues are whether WSCC practices concerning PSS tuning and operation are appropriate, and the role of HVDC controls in the August 10 breakup. Disturbance records for Palo Verde generator trips place that plant at the end of the PACI mode eigenvector, and suggest that very small injections of real power there would have quenched the PACI oscillations [4-5]. Do the enhanced planning models also indicate this - and do they replicate the Palo Verde trips?

HVDC effects may be a case of a disruptive limit cycle that was not visible to linear analysis. Concerns that mode switching might produce this are as old as the PDCI itself but, to my knowledge, the right combination of model and "killer case" has not been found before. Studies of voltage-referenced inverter control at Sylmar, reported in [1], changed the ratio of ac and dc swings but had little effect upon their sum or upon swing damping. This insensitivity has been observed many times and is a primary reason for the low priority previously assigned to full PDCI modeling. Using their enhanced model, could the authors provide the participation factors for HVDC involvement in the PACI mode, and those for the Palo Verde and/or San Onofre machines? Also, is there any information concerning performance of the SVC dampers near Sylmar?

[1] J. F. Hauer, "Reactive Power Control as a Means for Enhanced Interarea Damping in the Western U. S. Power System-A Frequency-Domain Perspective Considering Robustness Needs," Application of Static Var Systems for System Dynamic Performance, IEEE Publication 87TH0187-5-PWR, pp. 79-92.

[2] Evaluation of Low Frequency System Response: Study Results and Recommendations. Report of the WSCC $0.7 \mathrm{~Hz}$ Oscillation Ad Hoc Work Group to the WSCC Technical Studies Subcommittee, September 1990.

[3] J. F. Hauer, "Update on $0.7 \mathrm{~Hz}$ Dynamics in the Western Power System," BPA 1992 Engineering Symposium, March 31-April 1, 1992, Portland, OR, pp. 187-198.

[4] J. F. Hauer and J. R. Hunt, in association with the WSCC System Oscillations Work Groups, "Extending the Realism of Planning Models for the Western North America Power System," V Symposium of Specialists in Electric Operational and Expansion Planning (SEPOPE), Recife (PE) Brazil, May 19-24, 1996.

[5] J. F. Hauer, D. J. Trudnowski, G. J. Rogers, W. A. Mittlestadt W. H. Litzenberger, and J. M. Johnson, "Keeping an Eye on Power System Dynamics," IEEE Computer Applications in Power, pp. 50-54, October 1997

Manuscript received February 18, 1998.
P. Donalek (Harza Engineering Co., Chicago, IL): Would the authors comment on the usefulness of the simulation models as a basis for a study of system stability aids? Specifically, could the model be used to make a study of the effectiveness of a proposed pumped storage hydro plant connected at the Captain Jack substation? It has been suggested that if the proposed pumped storage plant had been in operation and if the plant had adjustable speed machines, then it could have prevented the spread of the disturbance into the California system. For a description of this suggestion see "System Reliability Improvement with Adjustable Speed Machines." The letter was published on page 45-46 of the February 1998 issue of IEEE Power Engineering Review; vol. 18, no. 2.

Manuscript received June 1, 1998.

Dmitry Kosterev, Carson Taylor, and Bill Mittelstadt: We thank Messrs. Morison, Yirga, Kundur, Donalek, and Hauer for insightful discussions.

Response to Kip Morison, Solomon Yirga, and Dr. Prabha Kundur (Powertech Labs): We see the August 10, 1996 WSCC system outage as a broader system phenomenon than a small signal stability problem. Although the instability was manifested in growing oscillations, the outage resulted from operating the power system under very stressed conditions with several transmission facilities out-of-service compounded by unforeseen factors.

Pacific Northwest generation patterns have changed due to anadromous fish recovery programs limiting number of hydro generating units on the lower Columbia River. As the paper describes, power flows characterized by high generation on the upper Columbia River, and high imports from Canada lengthen the Northwest-California transmission path. Low generation in the lower Columbia reduces dynamic reactive power and inertial support for the ac and dc interties. The electrical center of the north-south oscillations also moves further north, closer to the Celilo HVDC terminal. With such generation pattern, the system is more susceptible to power oscillations. On August $10^{\text {th }}$, outages of several $500-\mathrm{kV}$ lines in the lower Columbia area and Keeler-Allston 500-kV line further increased the north-south angular separation and caused reactive power deficiency in the Northwest. The BPA-developed phase angle monitor indicated that the relative phase angle between the Grand Coulee and Malin $500 \mathrm{kV}$ busses increased from 59 degrees to 69 degrees following the Keeler-Alston $500 \mathrm{kV}$ line outage. The AGC action following McNary tripping spread the inter-area angle further. At that time, if not growing oscillations, insufficient synchronizing power or voltage collapse would likely have caused the system breakup; see SCADA recordings in Figure 5. Other contributing 
factors were units operating on power factor control and operator intervention at a key unit to disable voltage control.

Our sensitivity studies clearly demonstrate that by reducing the north-south electrical distance (inserting series capacitors at Fort Rock) and providing additional reactive power support (shunt capacitors at Hanford and John Day) the August 10,1996 outage could have been prevented. Other sensitivity studies demonstrate that had the McNary units not tripped, the system would have remained stable.

We agree that low-frequency oscillations in WSCC, $0.2-0.33 \mathrm{~Hz}$ Pacific intertie mode, should be addressed by proper tuning of power system stabilizers. This is further discussed in response to Dr. Hauer. We have been investigating feasibility of reactive power modulation and switching to provide additional positive damping to the system. We designed and implemented AC.Voltage Dependent Current Order Limiter at Pacific HVDC Intertie to correct the $\mathrm{PDCl}$ dynamic response for low ac voltage conditions at Celilo. The new function is an emergency controller which releases reactive power from the converter when ac voltages are depressed and also can provide positive damping.

Negatively-damped oscillations can be created in a computer program in different ways. According to the discussors' reference, their load model in BC Hydro and the Northwest was changed to constant $\mathrm{P}$ and $\mathrm{Q}$ models to create negative damping without regard to actual estimated load composition and characteristics. Our purpose, however, was to realistically simulate the instability mechanisms. While we agree that load models have the most significant impact on the system damping, we do not think use of static load models (particularly constant power models) is the best approach. A good fit for a particular condition may not be a good fit for other conditions. The effect of dynamic loads on damping is known; see reference 7.

We investigated various load. characteristics and concluded that the most realistic load representation included dynamic representation of motor load. Saturday August $10^{\text {th }}$ was a very hot day through the western states and assumption of air-conditioning load, along with irrigation and other pumping load, is very reasonable. While more investigation is desirable, we see no reason not to model estimated motor load as aggregated dynamic devices.

We are convinced that the detailed HVDC model is essential for accurate reproduction and understanding of the event. Especially important is the multi-terminal representation of PDCI, and the control differences of the mercury-arc and thyristor converters. According to the discussors' reference, it was necessary, using their simplified single terminal HVDC model and controls, to raise the minimum firing angle from 5 to 9 degrees to somewhat approximate the PDCI behavior. Again, this is a change to fit the system response that doesn't have a physical basis.

$\mathrm{PDCI}$ is a major transmission element in the WSCC system, transferring up to $3100 \mathrm{MW}$ of power, and its detailed representation is essential for the inter-area studies. Inadequate modeling of Pacific HVDC Intertie in WSCC stability program resulted in $150 \mathrm{MW}$ reduction of the operating nomogram for 1997 Summer season. WSCC Modeling and Validation Working Group set detailed HVDC representation as one of the top modeling priorities in WSCC production programs.

We agree that eigenanalysis complements timedomain simulations. Eigenvalues and mode participation factors can identify controls that need retuning. Controllability and observability indexes indicate the most effective location for damping controllers (such as SVCs) and the input signals providing robust performance. Such studies require complete system representation. For special wide-area controls, however, we are finding that non-linear controllers, developed mainly by time simulation, are producing more robust performance.

Response to Dr. John Hauer: Dr. Hauer offers both a broad perspective on root causes of the summer 1996 disturbances and many specific comments. We agree that power company engineering resources have declined over the last decade with downsizing because of ever increasing cost pressures. As in other industries, we must now do more with less, hoping that technology advances can compensate for smaller staffs.

Although reliability tends to be gradually neglected during extended periods without major outages, the stated policy is that reliability must not be compromised with restructuring (just as airline deregulation did not compromise safety). This will be difficult, but possible, in future power systems. Transmission companies, working together and with owners of other power system components, will bear primary responsibility. New organizations such as security coordination centers, and new mandatory standards may help. Information technology to improve on-line security assessment is required

Both the WSCC System Oscillations Work Group and the WSCC Modeling Work Group (groups now merged) provided recommendations that were approved, but not implemented. Modeling Work Group load modeling recommendations are similar to IEEE/PES recommendations [6].

We think the WSCC PSS tuning and operation practices are generally adequate. The main problem for Pacific Northwest units has been hardware-related noisy frequency transducers and old analog stabilizers. Newer accelerating power stabilizers are more effective. Upgrading of over 100 hydro units is costly and time consuming. Several large plants have dc commutator exciters that make PSS less effective.

Regarding further use of the detailed multi-terminal $\mathrm{dc}$ model, we will report results in future papers.

As far as on-line monitoring, the BPA has taken several significant steps in this direction. A reactive reserve monitor is implemented to alarm operators when reactive reserves at lower Columbia hydro plants are becoming too low. The BPA also designed and implemented a Phase Angle Monitor, which alarms a dispatcher when the phase angles between Coulee, John Day, and Malin are exceeding safe operating limits. 
The BPA also initiated a probing signal project, when an operator can inject a step input in the PDCI current order to stimulate the ac system response. On-line analyzers will compute damping of power oscillations to ensure that the system has sufficient positive damping margin.

Response to Peter Donalek: The developed simulation model is being used for testing various stability aids such as supplementary controls applied to existing static var compensators, the Slatt thyristorcontrolled series capacitor, and switched shunt capacitors at Malin. Any device improving voltage support to California-Oregon Intertie, as suggested pump storage plant, should be beneficial for the system stability. Implementation and operational costs of any solution should be carefully evaluated.

In summary: The discussion and closure process adds to the value of the paper, and to the documentation of the power failure. Because of the importance of this outage to the power industry, we offer the following concluding comments.

The WSCC has made simultaneous transfer rating determination process much more rigorous. Season by season studies are made, with the challenge being development of more accurate and less manpower intensive on-line security assessment. Generator modeling is being improved by a WSCC-wide power plant testing program. Controls such as overexcitation limiters will be routinely modeled. Multi-terminal HVDC models will be used in future studies. Challenges remain for the modeling of loads and prime mover controls.

Beyond the modeling, simulation and control design/tuning issues, it's evident that many factors contributed to the severity of the August $10^{\text {th }}$ failure. The many recommendations of reference 1 of the paper are being implemented.

Except for the July 2, 1996 event [8], the undamped/negatively damped intertie oscillations were the first observed since 1976 [9] — which was the last previous year with excellent hydroelectric generation conditions in the Pacific Northwest and British Columbia. The 1976 oscillations occurred during light load hours with high power transfers from Canada to California, and with low generation at lower Columbia River plants.

Following the instability, the cost of the breakup was greatly increased because a controlled separation scheme was out of service, and because of the undesirable tripping of generators in the southern islands despite adequate underfrequency load shedding. The WSCC has taken steps to restore use of the NE/SE Separation Scheme which islands the northern and southern parts of the WSCC grid for loss of the California Oregon Intertie, and enhance it with selective load tripping.

We conclude that defense-in-depth is essential to limit cascading and prevent rare combinations of factors from causing very costly power failures. The modeling issues discussed are critical elements in preventing future failures.

\section{References}

[7] J. M. Undrill and T. F. Laskowski, "Model Selection and Data Assembly for Power System Simulation," IEEE Transactions on Power Apparatus and Systems, Vol. PAS-101, No. 9, pp. 3333-3341, September 1982.

[8] C. W. Taylor and D. C. Erickson, "Recording and Analyzing the July 2 Cascading Outage," IEEE Computer Applications in Power, Vol. 10, No. 1, pp. 26-30, January 1997.

[9] R. L. Cresap, D. N. Scott, W. A. Mittelstadt, and C. W. Taylor, "Damping of Pacific AC Intertie Oscillations via Modulation of the Parallel Pacific HVDC Intertie," CIGRE 14-05, 1978.

Manuscript received June 29, 1998. 